\title{
Escasos beneficios "antienvejecimiento" del tratamiento con andrógenos en mayores asintomáticos
}

Scarce anti-aging benefits of androgen treatment in asymptomatic old people

Nair KS, et al. N Engl J Med 2006;355(16):1647-59.

\section{Objetivo}

Evaluar los beneficios de la dehidroepiandrosterona (DHEA) en hombres y mujeres mayores y de la testosterona en hombres mayores sobre algunos parámetros asociados al envejecimiento.

\section{Diseño}

Ensayo clínico, aleatorizado, doble ciego, controlado con placebo.

\section{Lugar}

Mayo Clinic, Rochester (EE.UU.) y Universidad de Padua, Italia.

\section{Población}

Pacientes de 60 o más años: 57 mujeres con niveles de DHEAS (forma sulfatada de DHEA) y 87 hombres con niveles de DHEAS y testosterona por debajo del percentilo 15 de los normales para jóvenes de su sexo.

\section{Intervención}

Durante dos años 27 mujeres recibieron un comprimido de $50 \mathrm{mg} /$ día de DHEA y 30 , placebo. 29 hombre recibieron un comprimido de $75 \mathrm{mg}$ de DHEAS más un parche de placebo, $27,5 \mathrm{mg}$ de testosterona transdérmica y un comprimido de placebo y 31 , un comprimido y un parche de placebo.

\section{Medición de resultados principales}

Desempeño físico (pico de capacidad aeróbica como máximo volumen de oxígeno consumido por minuto y fuerza muscular) composición corporal, niveles de glucosa e insulina en ayunas, densidad mineral ósea (DMO) y calidad de vida.

\section{Resultados}

Se observó un aumento leve pero significativo de la masa magra y una disminución significativa de la grasa corporal $(1,5 \%)$ en hombres y mujeres que recibieron DHEA. Los hombres tratados con testosterona tuvieron un aumento significativo de la masa magra. Las mujeres tratadas con DHEA tuvieron un aumento leve pero significativo de la masa ósea en el radio distal y los hombres tratados con DHEA o testosterona tuvieron un aumento significativo de la masa ósea en el cuello femoral (ver tabla 1). No hubo efectos sobre el resto de los parámetros evaluados.

Tabla 1: diferencia mediana entre los grupos asignados a recibir andrógeno y los asignados a recibir placebo.

\begin{tabular}{|c|c|c|c|c|}
\hline \multirow{2}{*}{\multicolumn{2}{|c|}{$\begin{array}{l}\text { Diferencia de } \\
\text { medianas }\end{array}$}} & Mujeres mayores & \multicolumn{2}{|c|}{ Hombres mayores } \\
\hline & & $\begin{array}{l}\text { DHEA vs. placebo } \\
\text { (IC95\%) }\end{array}$ & $\begin{array}{l}\text { DHEA vs. placebo } \\
\text { (IC95\%) }\end{array}$ & $\begin{array}{l}\text { Testosterona vs. } \\
\text { placebo (IC95\%) }\end{array}$ \\
\hline Sensibilidad a & la insulina & $-1,80(-5,02-1,10)$ & $-0,06(-3,41-3,20)$ & $2,01(-1,24-4,86)$ \\
\hline Masa magra & en $\mathbf{k g}$ & $0,62 \quad(-0,05-1,35$ & $0,87(0-1,78)$ & $1,39(0,65-2,15)$ \\
\hline $\begin{array}{l}\text { Densitometría } \\
\text { en } \mathrm{g} / \mathrm{cm}^{2}\end{array}$ & $\begin{array}{l}\text { cuello } \\
\text { femoral }\end{array}$ & $0-(0,01-0,02)$ & $0,02(0-0,04)$ & $0,03(0,01-0,05)$ \\
\hline & radio distal & $0,02(0,01-0,03)$ & $0(-0,01-0,01)$ & $0,01(0-0,01)$ \\
\hline
\end{tabular}

La administración de DHEA o de testosterona en personas mayores no tiene efectos beneficiosos sobre la composición corporal, el desempeño físico, la sensibilidad a la insulina, ni la calidad de vida.

Palabras clave: dehidro epialdosterona, testosterona, envejecimiento. Key words: de hydroepiandrosterone, testosterone, aging.

Fuente de financiamiento: National Institutes of Health, Mayo Clinic y Mayo Foundation.

\section{Comentario}

Con el aumento de la edad se observa una declinación de las concentraciones de testosterona en el hombre y de DHEA y DHEAS en ambos sexos, ${ }^{2}$. Uno de los posibles abordajes de tratamiento de los trastornos asociados con el envejecimiento es el reemplazo de las hormonas que declinan con la edad. Este trabajo nos brinda valiosa información acerca del efecto del tratamiento de reemplazo con DHEA o testosterona durante dos años en una población mayor de 60 años. La duración del tratamiento y el diseño de esta investigación aumentan el valor de los resultados que, en resumen, muestran la escasa utilidad de estas hormonas como tratamiento de algunos de los fenómenos físicos y metabólicos que acompañan al envejecimiento. Para la interpretación de los resultados es importante tener presente que el objetivo principal de los autores fue evaluar el beneficio del reemplazo hormonal en sujetos seleccionados por edad y nivel de hormonas circulantes y no en base a la presencia de signos o síntomas asociados con el déficit hormonal. Por lo tanto estos resultados no pueden ser extrapolados a los efectos del tratamiento de reemplazo hormonal (con testosterona o DHEAS) en pacientes que presentan signosintomatología o antecedentes personales que se asocien con estos déficits hormonales.

Es necesario diferenciar el reemplazo hormonal como tratamiento "antienvejecimiento" del reemplazo hormonal en pacientes mayores sintomáticos con déficit hormonales. En este sentido, se ha demostrado el beneficio de sustitución con DHEA en mujeres con insuficiencia suprarrenal primaria o secundaria, en términos de mayor sensación de bienestar general y mejor actividad sexual ${ }^{3}$. También se ha demostrado la mejoría de la masa ósea y la disminución de la masa grasa en pacientes mayores deficientes de testosterona, tratados con este andrógeno a lo largo de tres años ${ }^{4,5}$, con mayores beneficios cuanto más baja es la testosterona previa al tratamiento.

\section{Conclusiones del comentador}

El tratamiento de reemplazo hormonal no parece de utilidad en pacientes asintomáticos con bajos niveles hormonales; debería aconsejarse sólo en pacientes con síntomas de insuficiencia hormonal y déficit hormonal comprobado.

Pablo Knoblovits [ Médico Especializado en Endocrinología y Andrología. Servicio de Endocrinología, Metabolismo y Medicina Nuclear, Hospital Italiano de Buenos Aires. ]

Knoblovits P. Escasos beneficios "antienvejecimiento" del tratamiento con DHEA o testosterona en personas mayores. Evid. actual. práct. ambul; 10(1): 9, enefeb.2007. Nair KS, Rizza RA, O'Brien P, Dhatariya K, Short KR, Nehra A, et al. DHEA in Elderly Women and DHEA or Testosterone in Elderly Men. N Engl J Med 2006;355(16):1647-59. PMID: 17050889. Texto completo disponible en http://content.nejm.org/cgi/content/full/355/16/1647

\section{Referencias}

1. Gray A, Feldman HA, McKinlay JB y col. Age, disease, and changing sex hormone levels in middle-aged men: results of the Massachusetts Male Aging Study. J Clin Endocrinol Metab. 1991;73:1016-25.

2. Orentreich N, Brind JL, Rizer RL y col. Age changes and sex differences in serum dehydroepiandrosterone sulfate concentrations throughout adulthood. J. Clin. Endocrinol. Metab. 1984;59:551-555

3. Arlt W, Callies F, van Vlijmen JC y col. Dehydroepiandrosterone Replacement in Women with Adrenal Insufficiency. N Engl J Med 1999; 341:1013-20.

4. Snyder PJ, Peachey $\mathrm{H}$, Hannoush $\mathrm{P}$ y col. Effect of testosterone treatment on body composition and muscle strength in men over 65 years of age. $\mathrm{J}$ Clin Endocrinol Metab 1999;84:2647-53.

5 . Amory JK, Watts NB, Easley KA y col. Exogenous testosterone or testosterone with finasteride increases bone mineral density in older men with low serum testosterone. J Clin Endocrinol Metab 2004;89:503-510. 